\title{
Coronavirus 229E Susceptibility in Man-Mouse Hybrids Is Located on Human Chromosome 15
}

\author{
Alan Y. Sakaguchi and Thomas B. Shows \\ Department of Human Genetics, Roswell Park Memorial Institute, New York State \\ Department of Health, Buffalo, New York 14263
}

Received 15 July 1981 -Final 14 September 1981

\begin{abstract}
Human coronavirus 229E, an enveloped, RNA-containing virus, causes respiratory illness in man and is serologically related to murine coronavirus $J H M$, which causes acute and chronic demyelination in rodents. $229 E$ displays a species-specific host range restriction whose genetic basis was studied in human-mouse hybrids. $229 E$ replicated in human WI-38 cells but not in three mouse cell lines tested (RAG, LM/TK-, and A9). Human coronavirus sensitivity (HCVS) was expressed as a dominant phenotype in hybrids, indicating that mouse cells do not actively suppress $229 E$ replication. HCVS segregated concordantly with the human chromosome 15 enzyme markers mannose phosphate isomerase (MPI) and the muscle form of pyruvate kinase (PKM2), and analysis of hybrids containing an X/15 translocation $[t(X ; 15)(p 11 ; q 11)]$ localized $\mathrm{HCVS}$ to the q11 $\rightarrow$ qter region of chromosome 15. HCVS might code for a specific surface receptor, allowing $229 E$ to be absorbed to and received within the host cell.
\end{abstract}

\section{INTRODUCTION}

Several human genes exerting control over the replication of a number of RNA and DNA viruses have been identified through parasexual means using cultured somatic cell hybrids (1-5). The somatic cell genetic approach has been a successful and currently necessary alternative to the use of animal hosts in studying the role of host genes in virus replication. One group of human viruses that are amenable to genetic analysis using somatic cell hybrids is the coronaviruses. Coronaviruses are enveloped, RNA-containing viruses causing a diverse group of diseases in man and other animals $(6,7)$. In 
man they are causative agents of a high proportion of respiratory illness and may be involved in diseases of other organs $(6,8,9)$. Relatively little is known about the genetic factors regulating infection caused by coronaviruses in their natural hosts. The prototype human coronavirus strain $229 \mathrm{E}$ provides a unique opportunity for investigating the genetics of susceptibility to coronavirus in vitro. 229E, as do most other coronaviruses, displays a narrow species-specific host range restriction, since it is capable of growing in a limited number of human cell types including cultured cells but not in rodent cells (6-8). This property allows a genetic dissection of host range restriction and cellular susceptibility to $229 \mathrm{E}$ using man-mouse cell hybrids since the virus permissive state is usually dominant in cell hybrids.

Because cell hybrids preferentially lose human chromosomes, each hybrid in a set of independent cell hybrids possesses a reduced complement of human chromosomes, while collectively the whole genome is represented (10). Correlation of susceptibility to infection with the presence of a specific chromosome in hybrids $(1-3,5)$ chromosomally assigns the gene. Using this strategy, the ability of $229 \mathrm{E}$ to form plaques on cell hybrids with different numbers and combinations of human chromosomes derived from several different human and mouse parental cells was determined. Our analysis indicates that the presence of the $\mathrm{q} 11 \rightarrow$ qter region of human chromosome 15 is required for susceptibility to this virus in vitro. The widespread occurrence of coronaviruses in the animal kingdom suggests that these viruses have evolved and diversified in parallel with the speciation of their respective animal hosts, more specifically, in parallel with a common host cell product necessary for virus infection. Based upon the known properties of $229 \mathrm{E}$, we suggest that the product of $H C V S$ might comprise part of a virus receptor, mediating entry of the virus into the cell.

The importance of identifying host genes involved in coronavirus infection derives from the observation that in certain animal species coronaviruses display a tropism for tissues of the nervous system. For example, the murine coronavirus JHM can experimentally cause acute and chronic demyelination in rodents (11-14) and persistent infection of neural-derived cells in vitro (15, 16). Moreover, $229 \mathrm{E}$ is serologically related to the neurotropic murine coronavirus JHM $(6,8)$. These virus-host cell systems are being studied as possible models for human demyelinating diseases, such as multiple sclerosis, which might have a viral etiology $(17,18)$.

\section{MATERIALS AND METHODS}

Parental and Hybrid Cells. WI-38 lung fibroblasts (ATCC, CCL 75) were used as representative parental human cells. Mouse parental cells with selectable markers were RAG $\left(\mathrm{HPRT}^{-}\right), \mathrm{LM} / \mathrm{TK}^{-}, \mathrm{LTP}\left(\mathrm{HPRT}^{-}, \mathrm{TK}^{-}\right.$, a derivative of $\mathrm{LM}^{-\mathrm{TK}^{-}}$), and A9 (HPRT $\left.{ }^{-}\right)$. Cells were grown in Dulbecco's 
modified Eagle's medium with $10 \%$ fetal calf serum and antibiotics (19). Human fibroblast-mouse hybrids used in this study included DUA (DUV $\times$ A9), DUM (DUV $\times$ RAG), WIL (WI-38 $\times$ LTP), RAS (SH $421 \times$ RAG), XTR (GM $194 \times$ RAG), ALR (AnLy $\times$ RAG), and TSL (GM $2808 \times$ LM/TK ${ }^{-}$). DUV (28), SH 421 (42), GM 194 (Mutant Cell Repository, Camden, New Jersey), GM 2808 (Mutant Cell Repository), and AnLy (19) are skin fibroblasts, while WI-38 is derived from fetal lung tissue. These six cell strains were originally isolated from unrelated individuals. The isolation and propagation of these cell hybrid series in hypoxanthine-aminopterinthymidine (HAT) selection medium has been described (19-21).

Virus Assay. Human coronavirus 229E (NIAID research reference reagent, Cat. No. V-361-001-021) was grown in WI-38 fibroblasts and was assayed by plaque titration (22). Virus pools had titers ranging from $10^{5}$ to $10^{6}$ plaque-forming units (PFU)/ml. Parental human and mouse cells and their derived hybrids were tested for susceptibility by either a cytopathic effect (CPE) assay or by plaque assay. For CPE assay, $2-4 \times 10^{4}$ cells in 0.1 $\mathrm{ml}$ of medium were seeded in 96-well Microtest plates (Falcon). The following day triplicate wells were exposed to $0.1 \mathrm{ml}$ of virus dilutions, and $\mathrm{CPE}$ was scored over the next 7 days of incubation at $33^{\circ} \mathrm{C}$. For plaque assay, $1-1.5 \times 10^{6}$ cells were seeded into $35-\mathrm{mm}$ plates and used the following day. Overlay medium consisted of fortified Eagle's medium (22) containing $2 \%$ bovine serum, $0.6 \%$ agarose (Seakem), hypoxanthine $(0.272 \mathrm{mg} / \mathrm{ml})$ and thymidine $(0.078 \mathrm{mg} / \mathrm{ml})$. Plaques were visualized after 7 days of incubation of plates at $33^{\circ} \mathrm{C}$ using overlay medium containing $0.033 \mathrm{mg} / \mathrm{ml}$ neutral red. Each dilution of virus was tested on triplicate plates.

Karyotype Analysis of Hybrids. Human metaphase chromosomes were identified in hybrid cells using the trypsin-Giemsa banding techniques (19).

Enzyme Marker Electrophoresis. The chromosome 15 markers mannose phosphate isomerase (MPI) and pyruvate kinase (PKM2) were determined by vertical starch gel electrophoresis as described (23). Gel electrophoresis procedures for enzyme markers assigned to each of the other 21 autosomes and the $X$ chromosome have been described $(24,25)$.

\section{RESULTS}

Virus Host Range. Human-rodent cell hybrids often express a variety of phenotypes characteristic of the parental cells from which they are derived, including susceptibility to viruses exhibiting a narrow host range (1-5). Human coronavirus $229 \mathrm{E}$ replicates in a limited number of human cell types but not in mouse cells (9-11). Human WI-38 cells and several mouse cell lines and their derivative human-mouse hybrid lines were screened for susceptibility to $229 \mathrm{E}$ to determine if human-mouse hybrids were susceptible to $229 \mathrm{E}$ and whether they could be utilized to study the basis for host range 


\section{PLAQUE TITRATION OF HUMAN CORONAVIRUS 229E IN PARENT AND HYBRID CELLS}

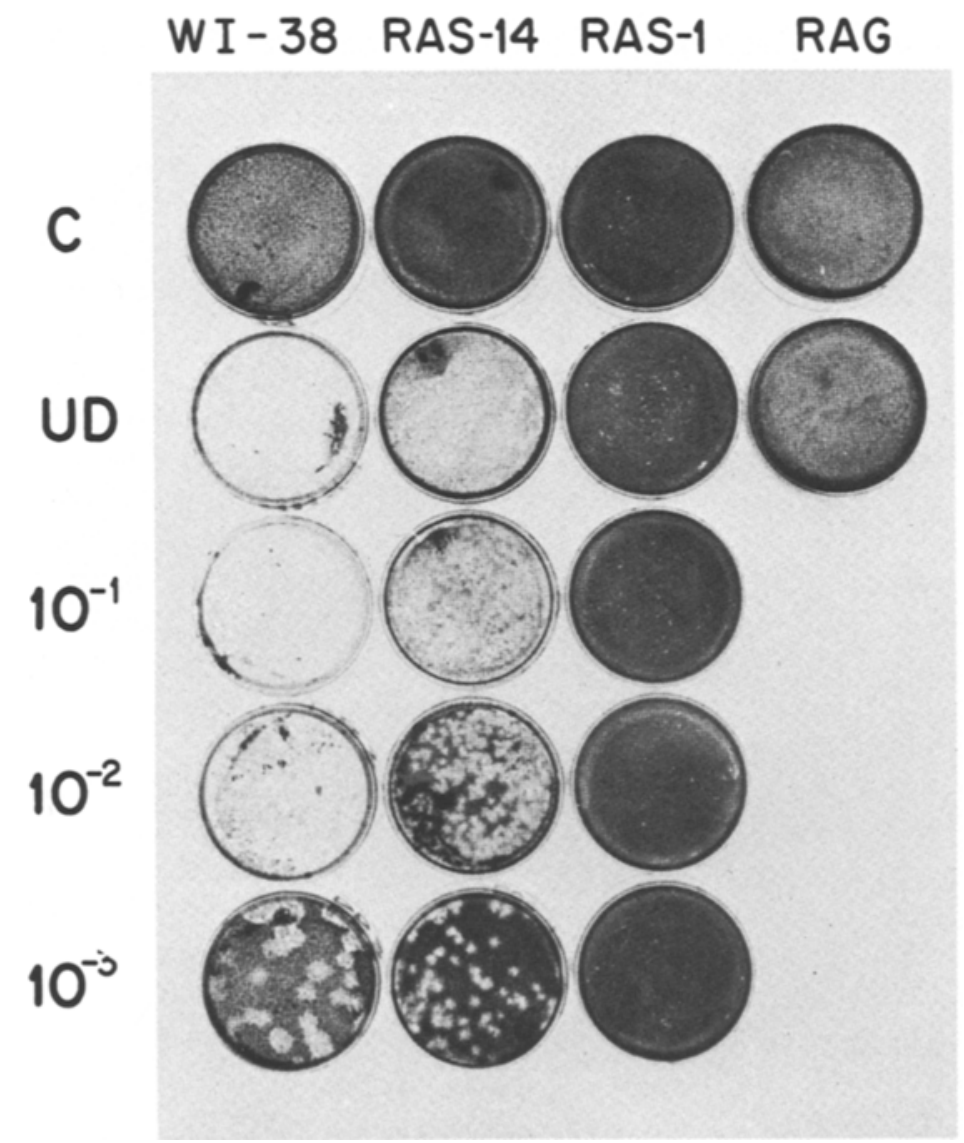

Fig. 1. 229E was titrated by plaque assay in parental WI-38 and RAG cells and in RAS-14 and RAS-1, two human-mouse hybrids. WI-38 and RAS-14 supported plaque production, whereas RAS-1 and RAG did not. Two other mouse parental lines, A9 and LM/TK - also did not support plaque production. $C=$ control cells not exposed to virus; $U D=$ cells exposed to the undilute virus pool.

restriction for this virus. If the nonpermissive state in mouse cells was dominant, 229E would not be expected to replicate in man-mouse hybrid cells regardless of their human chromosome composition. A plaque titration of 229E in human WI-38, mouse RAG, and two hybrid lines designated RAS 
are shown in Fig. 1. The upper row of plates are control cells not exposed to virus, whereas the next four rows are cells exposed to 10-fold dilutions of $229 \mathrm{E}$ beginning with the undiluted virus sample. The phenotype of RAS-14 was similar to that of WI-38, whereas RAS-1 resembled RAG cells which yielded no plaques after exposure to the undiluted virus sample (approximately $10^{5} \mathrm{PFU} /$ plate). The plaque titers of the virus sample in WI-38 cells and RAS-1 4 were similar, and the number of plaques obtained was proportional to the virus dose. The results indicate that some hybrids can be infected with $229 \mathrm{E}$, and they suggest that a human gene retained in some hybrid lines determined susceptibility to $229 \mathrm{E}$.

229E Plaque Production in Human-Mouse Hybrids. Thirty of the 32 hybrids used in this study were tested for susceptibility to $229 \mathrm{E}$ by plaque assay. The remaining two hybrids did not survive under agar for the 7 days required for the plaque assay and were therefore examined by CPE assay. These hybrids were constructed from four different mouse cell lines (RAG, LM/TK- , LTP, and A9) and human parental cells from six unrelated individuals. Eighteen of the hybrids supported 229E plaque production and yielded dilution titers similar to those obtained when the same virus sample was titrated in parallel in WI-38 cells. Table 1 demonstrates examples of

Table 1. 229E Plaque Production in Human-Mouse Hybrid Lines ${ }^{a}$

\begin{tabular}{|c|c|c|c|c|c|}
\hline \multirow[b]{2}{*}{$\begin{array}{l}\text { Hybrid } \\
\text { line }\end{array}$} & \multirow{2}{*}{$\begin{array}{c}\text { No. of } \\
\text { different } \\
\text { human } \\
\text { chromosomes }\end{array}$} & \multirow[b]{2}{*}{$\begin{array}{l}\text { Sensitivity } \\
\text { to } 229 \mathrm{E}\end{array}$} & \multirow[b]{2}{*}{$\begin{array}{c}\text { Presence of } \\
\text { chromosome } 15 \\
\text { and/or } X / 15^{b}\end{array}$} & \multicolumn{2}{|c|}{$\begin{array}{l}\text { Plaque titer of virus } \\
\text { pool }(\mathrm{PFU} / \mathrm{ml})\end{array}$} \\
\hline & & & & Hybrid & WI-38 \\
\hline DUA-1 & 3 & + & + & $5 \times 10^{4}$ & $1 \times 10^{5}$ \\
\hline DUA-5 & 11 & + & + & $5 \times 10^{6}$ & $2.9 \times 10^{6}$ \\
\hline DUA- 5 BSAG-A & 7 & $\because$ & - & 0 & $2.9 \times 10^{6}$ \\
\hline ALR-1 & 18 & - & - & 0 & $1.9 \times 10^{6}$ \\
\hline ALR-2 & 20 & + & + & $4.4 \times 10^{6}$ & $5.5 \times 10^{6}$ \\
\hline RAS-M4 & 18 & - & - & 0 & $1.9 \times 10^{6}$ \\
\hline RAS-8 & 20 & + & + & $3.9 \times 10^{6}$ & $5.5 \times 10^{6}$ \\
\hline XTR-1 & 16 & - & - & 0 & $1.9 \times 10^{6}$ \\
\hline XTR-8 & 23 & + & + & $4.5 \times 10^{5}$ & $4 \times 10^{5}$ \\
\hline WIL-8 & 20 & + & + & $3.5 \times 10^{5}$ & $1.8 \times 10^{5}$ \\
\hline WIL-12 & 12 & - & - & 0 & $4.7 \times 10^{4}$ \\
\hline
\end{tabular}

2229E was titrated by plaque assay on hybrid lines and WI-38 cells using 10-fold dilutions of virus. The figures represent the titer of a given virus pool when assayed simultaneously in WI-38 and the indicated hybrid line. A zero indicates that no plaques were observed in the hybrid line. 229E grows to relatively low titers in human cells, and it was therefore necessary to use several different virus pools for screening all the hybrids. This accounts for the variation in titers observed after plaque assays. The human chromosome content of hybrids was determined by enzyme assay and/or karyotyping. + and - indicates the presence and absence, respectively, of virus susceptibility and chromosome 15 or $\mathrm{X} / 15$ in the indicated hybrids.

${ }^{b}$ DUA hybrids are derived from a human fibroblast containing an $\mathrm{X} / 15$ translocation $[46, X, t(X ; 15)(\mathrm{p} 11 \rightarrow \mathrm{q} 11)](28)$. 
229E-sensitive and -insensitive hybrids derived from the different sets. of parental cells. No plaques were observed in RAG, LM/TK", or A9 cells exposed to comparable virus doses. These results indicate that sensitivity to $229 \mathrm{E}$ was transferred to these different mouse cell lines by fusion to several independently derived human parental cells obtained from the skin or lung.

Analysis of the replication of viruses with narrow host range has often revealed a diminution in virus output from hybrids formed from permissive and nonpermissive cells. For example, polyoma virus replicates in mouse cells but not in hamster cells. In mouse-hamster hybrids, late events in the polyoma virus replication cycle are suppressed by increased numbers of hamster chromosomes even when these hybrids contain a diploid number of mouse chromosomes (26). No suppressive effects of the mouse genome on 229E plaque production could be detected in hybrid cells using this qualitative assay. For example, the hybrid XTR-8 that contained all of the human chromosomes except the $\mathrm{Y}$ was as capable of supporting $229 \mathrm{E}$ plaque production as were parental WI-38 cells (Table 1). It appears here that sensitivity to $229 \mathrm{E}$ is a dominant phenotype in human-mouse hybrids.

One might surmise from the chromosome content of certain of the hybrids listed in Table 1 that sensitivity to $229 \mathrm{E}$ varies with small changes in the number of different human chromosomes that each line possesses. For example, ALR-2 which contained two more human chromosomes than ALR-1 (20 vs. 18, respectively) was sensitive to $229 \mathrm{E}$, while the latter hybrid was not. A similar result was obtained when RAS-9 (sensitive) was compared to RAS-M4 (not sensitive).

Because 229E grows to relatively low titers in cultured cells, it has not been practicable to determine virus outputs from infected hybrids. We have observed that plaque size varied in different hybrid clones but could not be correlated in a consistent fashion with the number of human chromosomes retained. However, 229E infection of a hybrid clone containing one human chromosome (DUA-1A, Table 3) yielded variegated lysis during plaque assays rather than distinct plaques.

The results suggest that a single human chromosome determines susceptibility to 229E in hybrids, although they do not rule out the involvement of other human chromosomes in virus replication. Thus it is possible that other host cell functions that might be required for virus replication can be provided by the mouse genome in hybrids.

Segregation of Virus Sensitivity with Human Enzyme Markers. For each hybrid line tested, a corresponding homogenate was prepared from the same passage of cells used for plaque or CPE assay. Each homogenate was analyzed by starch gel electrophoresis for the presence of enzyme markers previously assigned to each of the 22 human autosomes and the $\mathrm{X}$ chromosome. By comparing the results of such enzyme analyses with the virus assay data, it was possible to identify and assign a gene determining sensitivity to 
Table 2. Segregation of Human Coronavirus Sensitivity (HCVS) and Human Enzyme Markers in Human-Mouse Hybrid Clones ${ }^{a}$

\begin{tabular}{clcc}
\hline & & \multicolumn{2}{c}{ HCVS expression } \\
\cline { 3 - 4 } Chromosome & Marker enzymes & Concordant & Discordant \\
\hline 1 & AK2, PEPC & 23 & 9 \\
2 & ACP1, IDH1 & 20 & 12 \\
3 & ACY1 & 19 & 11 \\
4 & PEPS & 18 & 13 \\
5 & HEXB & 21 & 10 \\
6 & ME1 & 20 & 12 \\
7 & GUSB & 19 & 13 \\
8 & GSR & 16 & 15 \\
9 & AK1, ACO1 & 16 & 16 \\
10 & GOT1 & 22 & 10 \\
11 & ACP2, LDHA & 18 & 14 \\
12 & LDHB, PEPB & 21 & 11 \\
13 & ESD & 19 & 13 \\
14 & NP & 19 & 13 \\
15 & MPI, PKM2 & 31 & 11 \\
16 & APRT & 20 & 11 \\
17 & GALK & 21 & 10 \\
18 & PEPA & 24 & 14 \\
19 & GPI & 18 & 9 \\
20 & ADA & 23 & 13 \\
21 & SOD1 & 19 & 7 \\
22 & ACO2 & 18 & 11 \\
X & G6PD & 21 & 13 \\
\hline
\end{tabular}

${ }^{2}$ Symbols of enzymes, their chromosome assignments, and gel electrophoresis procedures have been previously described $(24,25)$. ACY 1 , aminoacylase-1, was determined by bioautography (25). Enzyme marker analysis and virus assays were performed on independent cell hybrid clones of the same passage. The figures under the concordant column represent hybrid clones in which HCVS and the enzyme markers were present or absent together. Figures under the discordant column represent hybrids in which the expression of HCVS did not correlate with the given enzyme markers. The involvement of the Y chromosome in determining HCVS could be eliminated since hybrids were derived from female human parental cells.

229E. Table 2 compares the segregation of human coronavirus sensitivity to $229 \mathrm{E}$. The HCVS phenotype best correlated with the expression in hybrids of the human chromosome 15 markers mannose phosphate isomerase (MPI) and the muscle form of pyruvate kinase (PKM2). HCVS segregated independently of all other human chromosomes. The single discordancy in which MPI and PKM2 were present while HCVS was absent is most likely due to chromosome breakage or could arise if only a very small proportion of hybrid cells in the population contained human chromosome 15 . Such small discordancy rates (3\%) have been observed for other linked genes using these hybrid cells (19-21).

Chromosome Analysis of $\mathrm{HCVS}^{+}$and $\mathrm{HCVS}^{-} \mathrm{Hybrids}$. Hybrid cells containing translocations involving the human $\mathrm{X}$ chromosome have proven to be powerful tools for gene mapping and regional gene assignments (27). The 


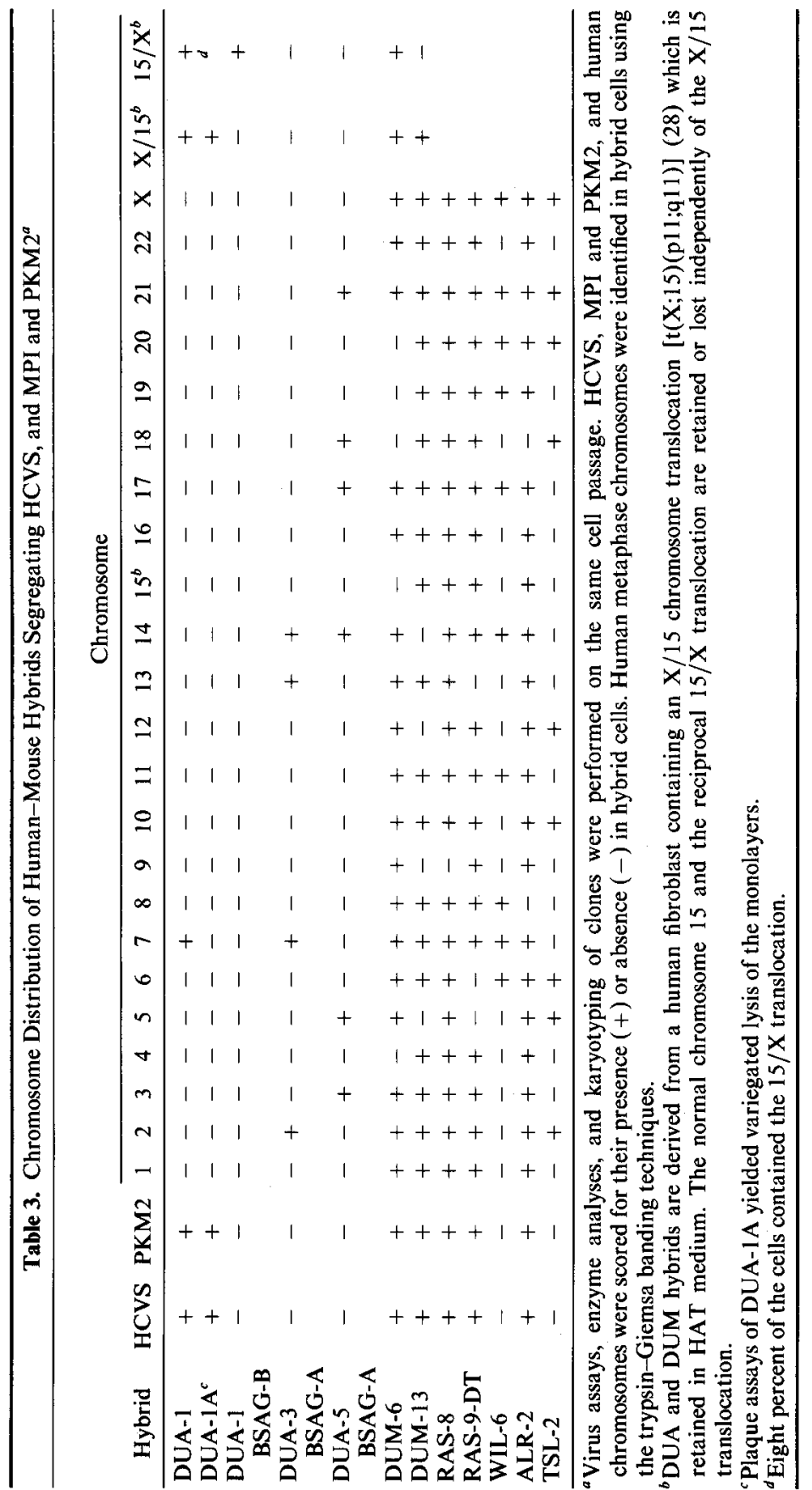


karyotypes of 12 hybrid lines were analyzed to confirm the results of marker enzyme analyses (Table 3), and these data indicated that HCVS segregated with the q11 $\rightarrow$ qter portion of chromosome 15 . This conclusion was based upon the following observations. Two series of hybrids, designated DUM and DUA, were constructed by fusing a human fibroblast strain containing an $\mathrm{X} / 15$ translocation (28) with RAG cells and A9 cells, respectively. HATsupplemented medium and 8-azaguanine could therefore be employed to select for and against (27), respectively, the retention of the X/15 translocation. Of the 12 hybrids, seven were susceptible to $229 \mathrm{E}$ and contained an intact chromosome 15 and/or X/15 translocation. The five hybrid lines in this group that were not susceptible to $229 \mathrm{E}$ did not contain an intact chromosome 15. DUA-1 contained human chromosome 7 and the $\mathrm{X} / 15$ translocation but not an intact chromosome 15 and was sensitive to $229 \mathrm{E}$ (Table 3). DUM-6 contained the X/15 translocation but not the intact 15 and was sensitive to 229E. Both DUM-6 and DUA-1 also contained the reciprocal $15 / \mathrm{X}$ translocation. However, it can be deduced that susceptibility to $229 \mathrm{E}$ segregates with the $\mathrm{X} / 15$ translocation (DUA-1A) and not with the $15 / \mathrm{X}$ reciprocal translocation (DUA-1 CSAZB). The independent secondary clones DUA-3 BSAG-A and DUA-5 BSAG-A, both counterselected in 8-azaguanine-supplemented medium, contained neither an intact chromosome 15 nor the X/15 translocation and both were not sensitive to $229 \mathrm{E}$. The possible involvement of chromosomes $X$ and 7 in determining the HCVS phenotype can be eliminated by the combined enzyme and karyotype data (Tables 2 and 3). Thus, the results of karyotyping are consonant with the enzyme marker data and support the idea that a gene or genes on the q11 $\rightarrow$ qter region of chromosome 15 regulate susceptibility to $229 \mathrm{E}$.

\section{DISCUSSION}

Human-mouse hybrids exposed to human coronavirus 229E confirmed the prediction that sensitivity to this virus is determined by the presence of a specific human chromosome in cell hybrids. Our results demonstrate that a gene or genes in the q11 $\rightarrow$ qter region of human chromosome 15 determines susceptibility to $229 \mathrm{E}$ in human-mouse hybrids. The results of plaque assays indicate that HCVS is expressed as a dominant phenotype in hybrid cells and that the virus replicated in hybrids containing human chromosome 15 or $\mathrm{X} / 15$ in three different mouse "genomic backgrounds" (RAG, LTP, and A9). Thus, these parental mouse cell lines and, likely, rodent cell lines, in general, do not actively restrict $229 \mathrm{E}$ replication. We conclude accordingly that the human genome contributes products that render human-mouse hybrids susceptible to $229 \mathrm{E}$.

Interspecies hybrids have been used for identifying genes controlling virus-host cell interactions at different steps in the virus replication cycle. 
The genes determining sensitivity to polio virus in primate cells and murine leukemia virus (MuLV) in mouse cells code for virus receptors that mediate the initial interaction of the virus with the host cell membrane $(1,29,30)$. Susceptibility to polio virus in human-mouse hybrids is a dominant phenotype and is determined by a polio virus receptor gene on human chromosome 19 (1). Nonpermissive mouse cells can support the replication of polio virus if exposed to infectious viral RNA, thus bypassing the requirement for virus receptors on the cell membrane involved in virus attachment (31). In contrast, sensitivity to herpes virus type $I$ is determined by a human gene product that acts at a postpenetration step $(2,5)$. It is apparent that $H C V S$ is not syntenic with previously described human genes on chromosomes $3,6,11$, and 19 (1-5) whose products are involved in the replication of other RNA- and DNA-containing viruses. Moreover, HCVS is not syntenic with the known human genes on chromosomes 9 and 21 , respectively, involved in either the production of or sensitivity to human interferons $(32,33)$. It seems that genes exerting control over virus-host cell interactions are widely spaced in the human genome. The functional implications, if any, of such a distribution, however, are not clear.

The man-mouse hybrids used in this study that were susceptible to $229 \mathrm{E}$ were constructed using human fibroblasts from five unrelated individuals. Apparently there is little genetic heterogeneity, as in all five sets of susceptible hybrids $H C V S$ mapped to chromosome 15. The $H C V S$ gene appears to be ubiquitous in the human population and is expressed in at least two different tissues (lung, skin).

A role for HCVS in the virus-permissive state is suggested by certain structural features of $229 \mathrm{E}$. 229E genomic RNA is of probable messenger sense $(7,34)$. As with polio virus, another plus strand RNA virus, 229E genomic RNA would be infectious even for mouse cells that are naturally insusceptible to the virus. It is likely that $229 \mathrm{E}$ species-specific host restriction is determined by the presence of appropriate virus receptors on the cell membrane. The product of the HCVS gene might comprise part of a virus receptor. Mouse cells, lacking such receptors, would be naturally resistant to $229 \mathrm{E}$, a situation analogous to and reminiscent of the polio virus system (1, $35)$. Tissue-specific expression of virus receptors is thought to determine the organ tropism of polio virus in man (36). A similar situation could account for coronavirus tissue tropism $(37,38)$, in which the expression of virus receptors in various cell types might differ quantitatively or be regulated by the phenotypic state of the cell.

The findings that susceptibility of human-mouse hybrids to $229 \mathrm{E}$ is determined genetically gain added importance in light of recent reports describing the presence of coronavirus-like particles in brain tissue taken from terminal patients with multiple sclerosis $(39,40)$. Moreover, the murine 
coronavirus JHM is currently being studied in vitro in cell cultures and in rodents as an animal model for human demyelinating diseases $(12-15,41)$, and this virus is serologically related to $229 \mathrm{E}(6,8)$. Human-mouse hybrids capable of supporting $229 \mathrm{E}$ replication will be useful for studying the molecular biology and interaction of human and murine coronaviruses using the same host cell, not heretofore practicable because of host range restrictions. Results from such studies could reveal key structural and genetic similarities between $229 \mathrm{E}$ and murine coronaviruses that have been shown to cause demyelinating disease in rodents.

\section{ACKNOWLEDGMENTS}

The excellent assistance of M. Byers, R. Eddy, L. Haley, and C. Young is very much appreciated. The important collaboration and consultation of Dr. J.A. Brown on previously published karyotypic analyses of the hybrids is gratefully acknowledged. We also thank Dr. S.L. Naylor for determining ACY1 by bioautography. This work was supported by National Institutes of Health grant GM 20454.

\section{LITERATURE CITED}

1. Miller, D.A., Miller, O.J., Dev, V.G., Hasmi, S., Tantravahi, R., Medrano, L., and Green, H. (1974). Cell 1:167-171.

2. Carritt, B., and Goldfarb, P. (1976). Nature 264:556-558.

3. Lemons, R.S., O'Brien, S.J., and Sherr, C.J. (1977). Cell 12:251-262.

4. Brown, S., Oie, H.K., Gazdar, A.F., Minna, J.D., and Francke, U. (1979). Cell 18:135143.

5. Francke, U., and Francke, B. (1981). Somat. Cell Genet. 7:171-191.

6. McIntosh, K. (1974). Curr. Topics Microbiol. Immunol. 63:85-129.

7. Tyrrell, D.A.J., Alexander, D.J., Almeida, J.D., Cunningham, C.H., Easterday, B.C., Garwes, D.J., Hierholzer, J.C., Kapikian, A., Macnaughton, M.R., and McIntosh, K. (1978). Intervirology 10:321-328.

8. Bradburne, A.F., and Tyrrell, A.J. (1971). Progr. Med. Virol. 13:373-403.

9. Zuckerman, A.J., Taylor, P.E., and Almeida, J.D. (1970). Br. Med.J. 1:262-264.

10. Ruddle, F.H., and Creagan, R.P. (1975). Annu. Rev. Genet. 9:407-486.

11. Cheever, F.S., Daniels, J.B., Pappenheimer, A.M., and Bailey, O.T. (1949). J. Exp. Med. 90:181-194.

12. Weiner, L.P. (1973). Arch. Neurol. 28:298-303.

13. Herndon, R.M., Price, D., and Weiner, L.P. (1975). Arch. Neurol. 32:32-35.

14. Nagashima, K., Wege, H., Meyermann, R., and ter Meulen, V. (1979). Acta Neuropathol. 45:205-213.

15. Lucas, A., Flintoff, W., Anderson, R., Percy, D., Coulter, M., and Dales, S. (1977). Cell 12:553-560.

16. Stohlman, S.A., Sakaguchi, A.Y., and Weiner, L.P. (1979). Virology 98:448-455.

17. Weiner, L.P., Johnson, R.T., and Herndon, R.M. (1973). N. Engl. J. Med. 288:11031110.

18. Johnson, R.T., and Herndon, R.M. (1974). Progr. Med. Virol. 18:214-228.

19. Shows, T.B., and Brown, J.A. (1975). Proc. Natl. Acad. Sci. U.S.A. 72:2125-2129.

20. Shows, T.B. (1972). Biochem. Genet. 7:193-204. 
21. Champion, M.J., and Shows, T.B. (1977). Proc. Natl. Acad. Sci. U.S.A. 74:2968-2972.

22. Hierholzer, J.C. (1976). Virology 75:155-165.

23. Shows, T.B. (1974). In Somatic Cell Hybridization, (eds.) Davidson, R.L., and de la Cruz, F. (Raven Press, New York), pp. 15-23.

24. Naylor, S.L., Klebe, R.J., and Shows, T.B. (1978). Proc. Natl. Acad. Sci. U.S.A. 75:6159-6162.

25. Naylor, S.L., Shows, T.B., and Klebe, R.J. (1979). Somat. Cell Genet. 5:11-21.

26. Green, H., Wang, R., Basilico, C., Pollack, R., Kusano, T., and Salas, J. (1971). Fed. Proc. 30:930-934.

27. Shows, T.B. (1979). In Genetic Mechanisms of Sexual Development, (eds.) Vallet, H.L., and Porter, I.H. (Academic Press, New York), pp. 255-271.

28. Solomon, E., Bobrow, M., Goodfellow, P.N., Bodmer, W.F., Swallow, D.M., Povey, S., and Noël, B. (1976). Somat. Cell Genet. 2:125-140.

29. Oie, H.K., Gadzar, A.F., Lalley, P.A., Russell, E.K., Minna, J.D., DeLarco, J., Todaro, G.J., and Francke, U. (1978). Nature 274:60-62.

30. Ruddle, N.H., Conta, B.S., Leinwand, L., Kozak, C., Ruddle, F., Besmer, P., and Baltimore, D. (1978). J. Exp. Med. 148:451-465.

31. Holland, J.J., McLaren, L.C., and Syverton, J.T. (1959). J. Exp. Med. 110:65-80.

32. Graves, H.E., and Meager, A. (1980). J. Gen. Virol. 47:489-495.

33. Tan, Y. H., Tischfield, J.A., and Ruddle, F. H. (1973). J. Exp. Med. 137:317-330.

34. Macnaughton, M.R., and Madge, M.H. (1978). J. Gen. Virol. 39: 497-504.

35. Wang, R., Pollack, R., Kusano, T., and Green, H. (1970). J. Virol. 5:677-681.

36. Holland, J.J. (1964). Virology 15:312-326.

37. Fenner, F., McAuslan, B.R., Mims, C.A., Sambrook, J., and White, D.O. (1974). The Biology of Animal Viruses, 2nd ed., (Academic Press, New York), pp. 338-393.

38. Tyrrell, D.A.J. (1979). Nature 280:194.

39. Tanaka, R., Iwasaki, Y., and Koprowski, H. (1976). J. Neurol. Sci. 28:121-126.

40. Burks, J.S., DeVald, B.L., Jankovsky, L.D., and Gerdes, J.C. (1980). Science 209: 933-934.

41. Haspel, M.V., Lampert, P.W., and Oldstone, M.B.A. (1978). Proc. Natl. Acad. Sci. U.S.A. 75:4033-4036.

42. Rattazzi, M.C., Brown, J.A., Davidson, R.G., and Shows, T.B. (1976). Am. J. Hum. Genet. 28:143-154. 